The role of evidence in nutrition policymaking in Ethiopia institutional structures and issue framing

Walls, Helen ; Johnston, Deborah ; Vecchione, Elisa ; Adam, Abdulfatah; Parkhurst, Justin

Published in:

Development Policy Review

DOI:

$10.1111 / \mathrm{dpr} .12385$

Publication date:

2019

Document version

Peer reviewed version

Citation for published version (APA):

Walls, H., Johnston, D., Vecchione, E., Adam, A., \& Parkhurst, J. (2019). The role of evidence in nutrition

policymaking in Ethiopia: institutional structures and issue framing. Development Policy Review, 37(2), 293-310.

https://doi.org/10.1111/dpr.12385 


\title{
The Role of Evidence in Nutrition Policymaking in Ethiopia: Institutional Structures and Issue Framing
}

\author{
Helen Walls, Deborah Johnston, Elisa Vecchione, \\ Abdulfatah Adam, and Justin Parkhurst
}

This chapter presents a version of a paper subsequently published as: Walls, Helen, Deborah Johnston, Elisa Vecchione, Abdulfatah Adam, and Justin Parkhurst. 2018. "The role of evidence in nutrition policymaking in Ethiopia: institutional structures and issue framing." Development Policy Review. https://doi.org/10.1111/dpr.12385.

H. Walls $(\bowtie) \bullet$ E. Vecchione

London School of Hygiene and Tropical Medicine, London, UK

e-mail: helen.walls@lshtm.ac.uk; e.vecchione@ucl.ac.uk

D. Johnston

SOAS University of London, London, UK

e-mail: dj3@soas.ac.uk
A. Adam
University of Copenhagen, Copenhagen, Denmark
e-mail: abad@sund.ku.dk
J. Parkhurst
London School of Economics and Political Science, London, UK e-mail: j.parkhurst@Ise.ac.uk
(C) The Author(s) 2018
J. Parkhurst et al. (eds.), Evidence Use in Health Policy Making, International Series on Public Policy, https://doi.org/10.1007/978-3-319-93467-9_3 


\section{INTRODUCTION}

Malnutrition is the single greatest contributor to the global burden of morbidity and mortality, affecting one in three people worldwide, with the majority of cases arising in low- and middle-income countries (LMICs) (Kassebaum 2014; Bhutta and Salam 2012). Initiatives to address this include including the 2025 World Health Assembly nutrition targets, the Sustainable Development Goal target of ending all forms of malnutrition by 2030 , and global initiatives such as the Scaling Up Nutrition movement (Gillespie et al. 2013; International Food Policy Research Institute 2015).

Nutrition policy involves collaboration between the agriculture, health and environment sectors (c.f. Gillespie et al. 2013; Mendis 2010; Bonita et al. 2013; Reinhardt and Fanzo 2014). However, this adds considerable complexity to the implementation of effective programmes (Balarajan and Reich 2016), with need for better understanding of the linkages between sectors to improve nutritional outcomes. Several countries have achieved considerable success with addressing malnutrition in recent years (WHO 2013). However, global progress has generally been slow, with many countries failing to achieve nutrition targets (International Food Policy Research Institute 2015; Roberto et al. 2015; Heaver 2005; Lachat et al. 2013).

Achieving nutrition goals requires policy action at the national level. This raises questions about why or how relevant policy change may come about within different country settings. As Chap. 1 in this volume discusses, the global health community has increasingly embraced the language of 'evidence-based policy' (or 'evidence-informed policy') to describe the ways in which research evidence provides clear policy solutions to health policy concerns. However, several case studies, including from LMICs, have illustrated the difficulties in applying these ideas in practice. NabyongaOrem and Mijumbi (Nabyonga-Orem and Mijumbi 2015), for instance, reflected on the Ugandan experience of evidence utilisation, stating:

although there is a general agreement on the benefits of evidence informed health policy development given resource constraints especially in lowincome countries, the definition of what evidence is, and what evidence is suitable to guide decision-making is still unclear. (p. 285)

Similarly, Shiffman (2006) found that, in aid-recipient countries, donor funding for communicable diseases did not reflect the evidence base on 
disease burden, which offer a rationale for prioritising policy action. Rather than there being any single process by which evidence is applied in policy development, complex political dynamics and normative ideas shape processes of evidence use (c.f. Nutley et al. 2007). The political nature of decision-making involves multiple contested interests, making it difficult to achieve agreement on which policy problems and policy outcomes should be prioritised (Parkhurst 2017). This has led Smith (2013) to argue that it more important to analyse ideas (about evidence) and how they shape policy rather than assuming evidence itself will have any consistent influence.

Ideas about evidence use exist collectively and are embedded within particular institutional norms and practices. Policy decision-making behaviours within institutions can thus be shaped and constrained by socalled 'logics of appropriateness' that serve to direct ways of working or thinking for individuals within particular institutional arrangements (Lowndes and Roberts 2013; March and Olsen 1984; Peters 2008). While the dominant way of thinking about evidence use to inform decisions in the global health community can therefore be conceptualised as one particular institutional logic, the multi-sectoral nature of nutrition policymaking raises questions about how health sector actors can engage with stakeholders that have differing priorities, and potentially different logics of evidence use.

Studying the process of nutrition policy formation can thus provide a useful lens to explore these issues of the roles and use of evidence in the context of multi-sectoral nutrition policy planning. Our perspective focusses primarily on the health sector yet our findings highlight different sectorial perspectives and logics in regard to a particular policy formulation. This chapter focuses on a case study of Ethiopia, which provides a unique example of the challenging nature of multi-sectoral nutrition policy-making, even with strong coordinating infrastructure. Although the government of Ethiopia implemented a National Nutrition Programme (NNP) in 2008 and integrated it with the overarching national strategic framework, the Growth and Transformation Plan 2010/11-2014/15 (GTP I) (Federal Democratic Republic of Ethiopia 2011), problems with multi-sectoral working have been acknowledged (Government of Federal Democratic Republic of Ethiopia 2016, pp. 20-21). Consequently, the structure for multi-sectoral working was strengthened in the third NNP, NNP-II (2016-2020) (Government of the Federal Democratic Republic of Ethiopia 2016) and in the GTP- II, 2015/16-2019/20 (Ethiopia 2016). 
This chapter illustrates the challenges with nutrition policymaking expressed by health sector stakeholders in interviews undertaken in December 2014. It examines the problems observed in multi-sectoral working from the health sector perspective. Furthermore, it uses these reflections on the likely success of NNP-II. It suggests that although Ethiopia has made progress with the coherence of its strategic planning, tensions remain with inter-sectoral alignment of nutrition concerns. The paper highlights three issues which we argue remain unresolved: the framing of nutrition in Ethiopia; the development of internal nutrition logics in complementary sectors; and the remaining gaps in the evidence base.

\section{The Case of Ethiopia}

Ethiopia has historically faced nutrition challenges in regard to drought and famine, and undernutrition remains a significant challenge in the country today (Hazards and Vulnerability Research Institute 2014). Nearly 8 million people in Ethiopia are considered to be chronically food insecure and thus supported through a national social protection programme, the 'Productive Safety Net Programmes' (aiming to "enable the rural poor facing chronic food insecurity to resist shocks, create assets and become food self-sufficient"), through multi-annual transfers of food and cash (World Food Programme 2017). Recent (2016) USAID figures indicate that 10 million more people are in need of emergency food assistance (USAID 2016).

Increasingly, however, Ethiopia is also facing problems of overweight, obesity and related non-communicable diseases (NCDs) (Zello 2015; Tebekaw et al. 2014), although this is mainly confined to urban settings. The 2011 Demographic and Health Survey estimated 6\% of women (aged 15-49 years) to be overweight or obese (Ethiopia Central Statistical Agency and ICF International 2012); a low prevalence by global standards (Malik et al. 2013). Yet, the 'double burden' of co-existing issues of underweight and overweight presents a new and significant challenge for Ethiopian nutrition policy (Walls et al. 2016b).

Ethiopia's political-administrative structures for nutrition policy have been shaped by its history of cyclical drought and famines, civil conflict and insurgency (Keller 1992; Webb and von Braun 1994) and, more recently food insecurity resulting from increasing climate variability (Kassie et al. 2013, 2014). Today, the Ethiopian Public Health Institute (EPHI) is the advisory body mandated to provide research and evidence to inform nutrition policy in the country. 
Historically, nutrition policy in Ethiopia was focused on acute or emergency food shortages (Embassy of the Federal Democratic Republic of Ethiopia 2016; Federal Democratic Republic of Ethiopia 1996). However, in recent years there have been efforts to establish broader and more systematic policy responses to nutrition driven by the need to address the Millennium Development Goals (MDGs) (Benson 2005; Ethiopian Academy of Science 2013), and provided the basis for the 2008 National Nutrition Strategy (NNS) (Federal Ministry of Health 2008).

A more comprehensive nutrition policy has been prioritised by the central government in Ethiopia in recent years. Ethiopia's first National Nutrition Programme (NNP) 2008-2013 acknowledged the role of multiple sectors including health, agriculture, education, and social affairs in addressing population nutrition, creating the National Nutrition Coordination Body (2008) and the National Nutrition Technical Committee (2009) and chaired and co-chaired by the State Minister of Health and State Minister of Agriculture and Natural Resources respectively (Ministry of Health 2015). The revision of NNP (resulting in NNP-I (2013-2015)) endeavoured to address problems arising from this multisectoral approach (Government of the Federal Democratic Republic of Ethiopia 2013). To supplement multi-sectoral working, the government established the National Nutrition Coordination Body (NNCB) and the National Nutrition Technical Committee (NNTC), with the intention of coordinating and mainstreaming nutrition into various sectors.

In terms of nutrition-related outcomes, official documents point to substantial declines between 2000 and 2015 in the prevalence of maternal anaemia, stunting, underweight children, and in anaemia among children under-five (Government of the Federal Democratic Republic of Ethiopia 2016). However, the prevalence of wasting remained fairly static (p. 13) (Government of the Federal Democratic Republic of Ethiopia 2016).

Overall, however, high levels of malnutrition remain. Related to this, NNP-II found that most ministries "have lagged in mainstreaming nutrition into their sectoral strategic plans. (Government of the Federal Democratic Republic of Ethiopia 2016, p. 21)." Sectoral departments lacked an effective organisational structure to mainstream nutrition; sectoral plans were not always reshaped to include nutrition goals; sectoral nutrition plans were not allocated a budget; responsibilities and accountabilities were not clearly defined around shared goals; and finally, the mechanisms to capture nutrition-relevant data from all sectors were not developed (Government of the Federal Democratic Republic of Ethiopia 2016). The NNP-II aimed to improve this situation by three broad sets of 
actions: strengthening the NNCB and local coordination bodies; requiring ministries to establish new nutrition capacity; and establishing both new evidence and new evidence-based decision-making systems (Government of the Federal Democratic Republic of Ethiopia 2016).

To date, there has been only limited research conducted on Ethiopian nutrition policymaking; with little explicit consideration of the role of evidence. Nisbett et al. (2015) explored leadership in tackling child undernutrition in Ethiopia and identified external challenges influencing individual leadership in nutrition policy, including a lack of local-level knowledge, evidence and data to inform policy. In particular, the authors highlighted the 'siloed' nature of local knowledge and data collection and advocated for a need to "look at the bigger picture and answer the big research questions" (Nisbett et al. 2015, p. 41). Kennedy et al. (2015), on the other hand, examined the governance of nutrition policy, finding general agreement at multiple levels on the nature of the problem, but various challenges such as limited leadership, funding, coordination, and incentives for inter-sectoral collaboration (Kennedy et al. 2015).

This study extends earlier research and provides more evidence of some of the challenges documented above. By engaging with the specific theme of evidence use to inform policy decision-making for nutrition in a context of multi-sectoral planning, it focuses on a key issue that has been identified as constraining multi-sectoral coordination.

\section{Methods}

The article draws on findings from 23 in-depth semi-structured interviews with stakeholders from key health sector organisations. The interviews were undertaken as part of a wider research project on the political aspects of evidence use for health policymaking in multiple countries Interviews focussed on key themes including: the structures and functions of evidence use within the Ethiopian health sector; the institutional mechanisms for evidence uptake; and investigation of the roles of evidence in influencing recent or important health policy decisions in the country; with a subset of five interviews also specifically exploring the theme of evidence use for nutrition policy. Interview data were combined with a documentary analysis of federal and relevant international strategies, plans and reports.

Key participants were identified though purposive and snowball sampling strategies. We endeavoured to conduct interviews with policy actors 
representing a diverse range of perspectives for the health decisions investigated. Participants involved senior and mid-level stakeholder representatives from a range of institutional types, including government (including from the Ministry of Health and Ethiopian Public Health Association), international donor agencies (including from UNICEF, Save the Children, the US Centers for Disease Control, and European Union), academic researchers and other independent non-for-profit groups (including from Addis Ababa University, the Ethipioan Academy of Sciences, and the Addis Continental Institute of Public Health), and corporate interests (including from the National Tobacco Enterprise).

Consent was obtained at the initiation of each interview, with respondents given options on levels of anonymity desired. Ethical approval was provided by the London School of Hygiene and Tropical Medicine; and research permission was obtained from the Ethiopian Public Health Institute. As part of the questioning about evidence use for health policymaking in Ethiopia more generally, respondents were asked for examples of particular health issues that could illustrate the application of the broader ideas and structures shaping evidence use. The respondents spoke about a range of issues, and nutrition was an important issue discussed by a number (5) of the respondents from a broad range of institutional types (government, academia and international donor agency), leading to further investigation into this issue and the analysis undertaken in this paper.

Analysis of interviews involved manual coding of key themes emerging from the interviews. This included reading the interview transcripts and recording key themes, and then cross-checking these themes through searches of key terms of emerging interest. To refine our understanding of the information from interviews, this information was then compared with and supplemented by that obtained from the documentary review.

In addition to the published academic sources cited throughout this paper, the documentary review included a set of unpublished sources related specifically to Ethiopia.

\section{Framing of Nutrition}

Despite wide embrace of the idea that evidence should inform policymaking, it has long been recognised that policy-relevant evidence is understood differently by different policy communities (c.f. Nutley et al. 2007; Parkhurst 2017; Weiss 1979). As such, it is important to consider how 
policy issues are framed and how this shapes which pieces of evidence, or what forms of evidence, are considered relevant. Unsurprising given its past famines, nutrition has historically been framed in Ethiopia as an acute or emergency issue. According to one interviewee, this focus could also be seen to affect the research agenda on nutrition in the country:

My impression is there is a lot of research especially on emergency nutrition... food shortage and acute malnutrition and that seems to affect a significant part of the population and it has been a constant focus for many NGOs and the government. So much of the research that I have seen is usually around this. (IDI ${ }^{1}-17$ )

As described above, many recent policy documents further illustrate the Government of Ethiopia's focus on undernutrition, with an emphasis on key population groups such as children and mothers. These policy documents have considerably less focus on nutrition problems linked to overweight. In the NNP-I (2013-2015), for instance, the word 'obesity' is mentioned once, in regard to its increasing prevalence in urban areas, while 'overweight' is not mentioned at all (Government of the Federal Democratic Republic of Ethiopia 2013). Yet our health sector respondents spoke frequently about a shifting conceptualisation in which nutrition as a chronic issue - particularly in regard to overweight/obesity - was of increasing importance in policy considerations:

We have a high prevalence who are underweight, but we also have overweight, which is coming... The $M O H$ has already prioritised both under and over nutrition because you will be surprised, you know in Addis and in the other city, in Dire Dawa, you see overweight is also a problem. (IDI-17)

Government policy documents such as the HSTP describe how risk factors for overweight, obesity and NCD, including physical inactivity and unhealthy diets, are widely prevalent in Ethiopia; and particularly in urban areas (Ministry of Health 2015). The NNP-II (2016-2020) (Government of the Federal Democratic Republic of Ethiopia 2016) has more information relating to overweight and obesity, and also includes an indicator on overweight women. However, no indicators relate to overweight children, and core goals and objectives remain focused on undernutrition. The perception of respondents was thus that any recent shift in research and evidence generation to focus on overweight/obesity and associated NCDs as

${ }^{1}$ IDI refers to in-depth interview, with anonymous numbers assigned. 
described during fieldwork 2014, largely remained at odds with the national policy response; which was felt to only minimally address overweight and obesity in national strategies.

One potential explanation for this could be that global framings or conceptualisations regarding nutrition were being picked up in local discourses - even if it appears to a much lesser extent in existing policy. The international literature has increasingly in recent years linked undernutrition with overweight and obesity-related health issues, and there has also been a dominant discourse in the global health community on the need for more multi-sectorial and structural policy responses to addressing nutrition (Kanter et al. 2015; Ruel et al. 2013; Dangour et al. 2013; Garrett and Natalicchio 2011; World Bank 2013). Such a push would address the underlying causes of malnutrition. This framing was also identified in local interviews, with individuals in four separate interviews raising the issue.

It's now established, there are many studies which have proved this, people who have been affected by under nutrition during childhood in the first years of life, these are critical years, and ... they will have a much higher risk of hypertension, overweight, obesity. (IDI-17)

The $\mathrm{MoH}$ [is the main actor in recent nutrition policy] and the second we can consider the other actors for example other sector, actually the nutrition issue is not only for the health issue it is the concern of other sectors like agriculture, education, water, actually nine sectors are involved [in revising the NNP]... Nutrition is a multsectoral and multidimensional issue. (IDI-23)

This thinking, however, was reflected in national documents as well. The HSTP, for instance, describes nutrition as a 'cross-cutting' issue (Ministry of Health 2015), and two of the five objectives of NNP-I and NNP-II relate to this emphasis on multi-sectoral action (Government of the Federal Democratic Republic of Ethiopia 2013). The Situation Analysis of the Nutrition Sector in Ethiopia also reflects this focus, with suggestions for greater multisectoral efforts, including a policy recommendation to 'revisit existing agricultural politics to make them nutrition sensitive with a clear result framework' (p. 85) (FMoH/UNICEF/EU Situation Analysis of the Nutrition Sector in Ethiopia: 2000-2015 2016).

There was a suggestion from interviewees that this view in Ethiopia of nutrition as a multi-sectoral issue may particularly have been influenced by the 2008 Lancet nutrition series, which happened to be launched in Addis Ababa. As respondents explained: 
Nutrition is not only public health, it's many other aspects. Like even globally even if you look at [it] from the Lancet for example the cause of stunting only $20 \%$ is nutrition-specific the other is nutrition-sensitive which is not related health. So we are saying that nutrition is beyond the health. (IDI-13)

So one of the issues is actually the fact it needs really multi-sectoral action, and that is a big challenge and I was there following the launch of that [Lancet] strategy.... (IDI-17)

\section{Challenges to an 'Upstream' and Multisectoral Approach}

The 'upstream/downstream' metaphor commonly used in public health captures concerns between paying attention to prevention versus treatment of health issues; with prevention about consideration of the causes of health problems (Dorfman and Wallack 2007). An upstream focus would address the more distal causes of the problem, sometimes described as the 'causes of the causes' (Marmot 2005), and with nutrition might be addressed through leveraging agricultural policy or larger politicaleconomy drivers (Balarajan and Reich 2016). A downstream focus would be more proximal to the individual, focused perhaps on education and information, or provision of micronutrient supplements.

Whilst there may be a growing recognition and desire to respond to nutrition in an upstream or structural manner, policy interventions for nutrition globally have been described as traditionally focussing downstream - on potentially less effective, or less sustainable interventions (Walls et al. 2016a, b). Such interventions can more easily lend themselves to measurable (though not necessarily greatest) policy impact, and clearer evidence generation.

Our interviews identified criticisms of downstream approaches to addressing nutrition in Ethiopia, with one interviewee criticising the government for supporting a micronutrients approach, instead of 'an integrated dietary approach' which the respondent believed should start with food diversification and only rely on supplementation as a last resort (IDI17). The first version of the NNP (2008-2013), launched prior to this report, gave little emphasis to the micronutrients approach. In fact, the National Food Fortification Programme was among the chief reasons for revising the original NNP (Government of the Federal Democratic Republic of Ethiopia 2013). Since then, food supplementation in the form of vitamin A for children under 5 and zinc supplementation for diarrhoea treatment had been implemented. In addition, legislation requiring salt 
iodization has been put in place (Government of the Federal Democratic Republic of Ethiopia 2013).

Food fortification is considered a means to rapidly address nutrition challenges. Some health actors expressed the view that the reasons driving policy action in agriculture differ to those in health, and this reflected a more general challenge of enacting structural policy changes when doing so requires engagement from other sectors, especially the agriculture sector - seen to be key to a multi-sectoral nutrition response.

If you look at the causes of under nutrition it easily goes outside the health system. So one is for example food security, food security is a question of having sufficient land productive... the main target for the $\mathrm{MOH}$ is to decrease mortality and you can't do that without addressing undernutrition. So I think it makes sense to give this assignment to the $\mathrm{MoH}$ but there should be also a way to give it more power so that's the whole idea... The only thing is the MoH should have more strong department and representatives from all ministries. (IDI-17)

One respondent, for instance, explained that the MoA mandate is to increase productivity, and that it is evaluated by this target rather than on the nutritional outcomes of its policies per se. (IDI 13). This reflects the focus of the first GTP, as previously described (Federal Democratic Republic of Ethiopia 2011).

The advice to the public from the agricultural sector - advice regarding promotion of economic aspects of agricultural production and not its potential to improve nutrition - was considered by respondents to be unhelpful from a nutrition perspective, and even in contradiction to advice from the $\mathrm{MoH}$. Additionally, agricultural policy was considered not to be 'nutrition sensitive'.

[Much agricultural policy] now days is not nutrition sensitive, so the agriculture people are just contradicting some of the messages [from nutrition]. Sometimes they say 'just produce more and gain more money, not to eat', and sometimes they are just promoting only the saving issue and sometimes they are not just promoting issue related with the consumption of high food and vegetable consumption of dense food for the children especially for the under five children and for the mother. (IDI-13)

These findings resonate with a question raised by (Roberts 2008) as to whether it's a conflict of interest when an agricultural department is "expected to champion and protect both farmers who sell and consumers who buy the same product". 
Under GTP-2, the agricultural sector has a range of major targets (table 19, GTP-2) in the areas of production, food security, productivity, trade and marketing and input supply. These may often be complementary to the goals of NNP-2. For example, GTP2 contains targets for improvement in the number of production safety net recipients, the size of the food reserve and in cereal output. It also contains targets around increases in export earnings from major commodities, and these have a complex relationship to nutrition improvement, depending significantly on the pay and conditions of workers in export production (Cramer et al. 2017). In addition, the promotion of exports of food crops, most notably teff, the major staple of Ethiopia and hailed as a new 'superfood', may lead to sharp prices rises on local markets. Despite its success in earning scarce foreign exchange, there have been some criticisms of the partial lifting of export ban on teff, with concern that, however sensitive the policy was to nutrition concerns, it would reduce domestic food security (Secorun 2016; Reda 2015).

- One interviewee explained that there could be difficulties when consensus on the involvement of different governmental ministries could not be reached:

The whole idea of having a national overarching document was there for a long time before that... one of the issues which prevented the launch of even the document was to decide which ministry [should coordinate it], so... they told me that people at parliament and the Prime Minister's Office had to make the final decision. (IDI-17)

Even with the coordinating framework of the GTP and NNP, there can thus be obvious challenges when a policy problem is identified through one sector - in this case based on the indicators of malnutrition and related health - yet must be addressed by action within another sector (e.g. agriculture). There may be differences of opinion on the priority or importance of policy action, clashes in authority between departments who may vie for ownership of policy and interventions, and need for coordination and cooperation that adds additional levels of complication beyond what would be needed in single-sector policymaking (Pelletier et al. 2012; Hoey and Pelletier 201 1; Trivedi 2000; Mills 1990). Health sector respondents certainly described that, under NNP-I and GTP-I, nutrition was not sufficiently prioritised in the policy-making of other sectors and that nutrition targets were not sufficiently represented in overarching documents. 
These issues suggest questions as to why up-stream nutrition policymaking proved difficult under NNP-I. The interviews also throw light on key issues in the NNP-II, and reinforce the argument that for multisectoral policy making, the issue is not only one of aligning interests under GTP-II and NNP-II but also of developing capacity around nutrition in sectors and producing nutrition-relevant evidence. Crucially they suggest that for nutrition to be appropriately framed, the MoA needs to adopt an internal logic that aligns its productivity and trade goals enshrined in GTP-II with NNP-II goals, and devises and monitors policy using nutrition-relevant evidence. More fundamentally, this also requires discussion of trade-offs between multiple and at times competing interests and concerns typical within broader political thinking (Lasswell 1990 [1936]).

\section{IMPLICATIONS FOR 'EVIDENCE INFORMED' \\ Nutrition Policy}

The challenge of developing and implementing multi-sectoral policy is multifaceted, but interviewees raised two specific challenges in relation to evidence use and policy response. First, although multi-sectoral plans and infrastructure to address malnutrition were in place, the mandate for addressing nutrition lay with the health sector, which was reinforced by the nature of nutrition data collected or used.

Ultimately in terms of evidence use, however, this presents a situation whereby the evidence that has globally (and locally) provided the motivation for action - evidence such as under-five mortality, rates of diarrhoea and infections, prevalence of overweight and obesity - may not have the same importance to many of the key stakeholders required for sustainable, effective, policy action. This is because such evidence may not be judged as relevant by non-health stakeholders if their own institutional logics are based around a different normative position or set of goals. Indeed, respondents reflected on how the framing of relevant evidence could vary between the international discourse and the relevant local institutions cutting across a number of sectors - each with its own idea of what is relevant to justify policy action or inform policy decisions.

Respondents discussed the need for data and research evidence showing impacts on more than just health outcomes (e.g. educational or economic productivity) in order to achieve policy change. One respondent explained: 
The impact of malnutrition for example on economic development, you have to quantify it... you have to convert the malnutrition impact in money and the money for the national development. You have to convert the impact of malnutrition for example on education; if a child is malnourished the performance for education will be just... you can tell just like this [...] We get [information on] impact of malnutrition across different sectors. On health, on education on productivity ... At every advocacy place we are using those data actually. (IDI-23)

Indeed, as a way of providing multi-sectoral nutrition evidence, the Government of Ethiopia published a report: The cost of hunger in Ethiopia: Implications for the growth and transformation of Ethiopia, becoming the first country to engage in the Africa Union's Cost of Hunger exercise (African Union Commission, World Food Programme, and Africa 2012). This report provides economic costing of the long-term impacts of underfive undernutrition, exploring the cost of higher healthcare spending on this group, education costs when these people are in the school system, and the productivity costs as they enter the workforce - and estimates that in 2009 , the cost of child undernutrition was 55.5 billion Ethiopian Birr (16.5\% of GDP - approximately USD $\$ 4.3$ billion in Dec 2009).

Ethiopia's early involvement in the cost of hunger exercise demonstrates commitment to the creation of evidence relevant to other sectors. As such, it is a powerful tool to aid multi-sectoral policymaking, and provides evidence relevant to other targets in the GTP-2 plan. However, in itself, it only partially quantifies the goals of NNP-2. While NNP-2 is concerned with the undernutrition of young children, it is also concerned with the undernutrition of adolescents and women. Equally, our health sector respondents described how rising rates of overweight and obesity and their NCD impacts were relevant to nutrition policymaking. So the Cost of Hunger exercise appears only to provide a partial multi-sectoral evidence base.

A final challenge raised in our interviews, however, was the perception that multi-level data from across the country (including decentralised information) was also needed to inform an appropriate nutrition strategy, but that these data were not yet available in sufficient volume. One respondent, for instance, stated:

We are just starting to utilise the available resource at different levels. Information is important for different levels not only central level... I think within the next five years we can get a clear picture of information flow from across different sectors, horizontally as well as vertically. (IDI-23) 
These challenges in the evidence base may particularly undermine upstream intervention and planning - for nutrition or other health policy issues. Downie (2016) has described the Government of Ethiopia as particularly outcome oriented, with a centralised drive to achieve 'near term development goals' (pp. vi) While our study was not able to validate this claim, it is worth noting that if a principle focus of the government is for evidence that can show measurable outcomes aligned with core targets on undernutrition, this would presumably incentivise the use of forms of evidence that focus on immediate and direct impacts that can more easily be quantified, such as supplemental nutrition for acute malnutrition cases. The evidence base required for, and useful for, informing the addressing of and evaluating the impact of interventions targeting upstream structural determinants of health including nutrition are much broader, less certain, and often harder to quantify (Bonnefoy et al. 2007; Parkhurst 2017). Accordingly, the intervention types given the greatest attention may be those that are less likely to bring about more systematic and sustained progress over the longer term.

\section{Discussion}

The framing of nutrition in Ethiopia is changing, with greater discussion of considering malnutrition in all its forms: undernutrition and micronutrient deficiencies, as well as overweight, obesity and NCDs. Nutrition has also been seen at the highest level of Government as an issue that requires multi-sectoral action. However, our interviews provided a health sector perspective to the problems of target setting and evidence use.

Thus, while there has been a broader framing of nutrition amongst health stakeholders and to some extent in official nutrition policy, overweight- and obesity-related targets are less evident in key documents. While, in theory, responding to nutrition more holistically and multisectorally reflects the state of contemporary thinking about the most effective approach to addressing malnutrition, such approaches present particular challenges to the idea of an obvious body of evidence that can simply inform or guide policymaking. One way to understand the limits to this conceptualisation has been to apply an institutional lens, considering the structures in place that influence which evidence is brought to bear on policy decisions and the institutionalised logics that relate to evidence use, which may differ across agencies involved in nutrition policy. 
In public health, there is a recognised tension between the need for more structural interventions, and the realities that interventions focussing on treatment or downstream individual approaches can be easier to conceptualise, measure, and evaluate. Even with increased recognition or calls for upstream action, the existing data and evidence may focus policy action on downstream efforts, which appears to remain a challenge for nutrition policy in Ethiopia. Without a solution, this may continue to hamper the implementation of NNP-2.

The more recent 2016 Situation Analysis of the Nutrition Sector in Ethiopia document attempts to make agriculture in Ethiopia more nutrition-sensitive through the adoption of dietary diversity as an outcome indicator in the most recent iteration of the Agricultural Growth Program (AGP). It also describes how, for the agricultural sector, appropriate indicators of food security and dietary diversity should be chosen for evaluation of agricultural sector responsibilities (FMoH/UNICEF/EU Situation Analysis of the Nutrition Sector in Ethiopia: 2000-2015 2016). This suggests that while data may block how far dominant ideas may be able to progress in shaping policy, those ideas can work to re-shape which data are generated, potentially providing useful evidence for future approaches to nutrition policy.

An important insight into the challenges faced in evidence use to inform nutrition policy come from March and Olsen's institutional concept of the 'logic of appropriateness', which captures the ways that institutions develop their own internal norms, values, and understandings of how things should work, which are enacted in their operations (March and Olsen 1984, 2011). This idea provides an opportunity for reflection on the unexpected results that can arise when differing logics come into conflict in policy debates.

Different institutional norms, values and logics of appropriateness between the health and agricultural sectors were perceived by the health sector actors in our study (although we acknowledge that greater insight could be obtained by further work interviewing representatives of agriculture and other sectors). Despite the framing given by NNP and GTP, agricultural interests were often considered by our respondents to be driven by productivity targets and associated evaluation, without appropriate inclusion of nutrition objectives. This view resonates with the official acknowledgements of the weaknesses of NNP (above). Respondents also spoke of need for nutrition to be framed in terms of its impact on the country's economic development at times. However, such challenges are 
not unique to Ethiopia. Balarajan and Reich (2016) have described the challenges posed by different stakeholder narratives of nutrition globally (Balarajan and Reich 2016).

There are many targets that are complementary between sectors, and the The cost of hunger in Ethiopia: Implications for the growth and transformation of Ethiopia report helps identify these. In future, the new NNP-2 and GTP-2 may provide a framework to produce rapid progress on those areas where evidence suggests strong mutual gains. An example of such synergy is the fact that one of the initiatives of the NNP-I (2013-2015) was to "promote and disseminate bio-fortified micronutrient-rich staple food products, such as orange sweet potatoes and quality protein-rich maize." This initiative is under the direct influence of the MoA. By allocating necessary attention to this initiative, the MoA not only contributes to the realization of the objectives set forth in the NNP-1, and NNP-2, but also this is a core objective for the MoA itself. Obviously, these areas are particularly likely to advance strongly under the existing multisectoral coordination framework because they talk to evidence and targets that are equally recognised and valued.

\section{CONCLUSION}

This paper has discussed an area of acknowledged weakness in Ethiopia's multi-sectoral nutrition policy framework: that of the role of policymaking with varied, conflicting and missing evidence. It focuses particularly on health stakeholder perspectives, and thus can only explore some of the issues involved. Despite this, it illuminates three issues. First, it helps explain the problems in the coordination of mandates and evidence in NNP-1 and suggests likely areas for continuing challenge under NNP-2. Second, we have argued that there is still a lack of clarity about the role of upstream interventions, and despite a framework for integrating targets through NNP-2 and GTP-2, this may be worsened by the tension with some agricultural sector targets. Here the point is that unified frameworks result from tense, often unseen struggles between conflicting political goals. Third, despite the improvements in the evidence base, we argue that further evidence is needed to inform nutrition policymaking in Ethiopia, and that more evidence is needed to inform policy in non-health sectors on nutrition-specific interventions.

Even though Ethiopia has made progress in terms of nutrition targets and has a strategic framework aiming to address past problems, it shares 
the challenge of countries elsewhere in addressing nutrition as a multisectoral issue. It also provides a useful case of institutional logics and how assumptions about the type and role of policy-relevant evidence for nutrition policy action may not hold across sectors.

Our study takes place at a key moment in nutrition policy making in Ethiopia. Whilst we found that respondents were aware of a variety of nutrition problems and approaches to nutritional issues, our findings contrast with those of Kennedy et al. (2015), who described a 'general consensus' amongst their interview respondents that the 'nutrition problem' in Ethiopia is one of undernutrition (with respondents from a broad range of sectors). This difference may reflect the earlier (2013, rather than at the end of 2014) period of data collection, but may also reflect differences in the methodological and epistemological approach of the two studies. That said, the importance of the focus on undernutrition should not be underestimated. This was also recognised by our respondents as critical and a major challenge, but our research questions particularly endeavoured to probe about other aspects of nutrition policy beyond this dominant frame.

Finally, this paper explored the role that evidence and target-setting can play in informing and influencing the direction of policy development for nutrition. Rather than a simple one-way path from evidence to policy, the case of nutrition has shown the complex interaction of evidence within different conceptualisations of policy problems and responses. These processes play out in a setting where there is a strong steer to unified approaches at the national level. Evidence may not always easily speak to preferred policy responses, and the importance or relevance of different types of evidence may vary across sectors based on varying institutionalised logics by which they purse policy goals. Evidence is not fixed, with new constructions of data and evidence always emerging, and subject to influence by those stakeholders active in the particular policy arena. We thus expect to see continuing evolution of the body of evidence available to inform nutrition policy in Ethiopia, as well as potential changes in how different stakeholders conceptualise the importance of different evidence types.

Acknowledgements We are most grateful to the participation of the study respondents in this research.

This research was conducted as part of the Getting Research into Policy in Health (GRIP-Health) project, supported by a grant from the European Research Council (Project ID\#282118). 


\section{REFERENCES}

African Union Commission, World Food Programme, and United Nations Economic Commission for Africa. 2012. The cost of hunger in Ethiopia: Implications for the growth and transformation of Ethiopia. Addis Ababa.

Balarajan, Y., and M.R. Reich. 2016. Political economy challenges in nutrition. Globalization and Health 12: 70.

Benson, T. 2005. Improving nutrition as a development priority: Addressing undernutrition within national policy processes in sub-Sabaran Africa. Washington, DC: International Food Policy Research Institute.

Bhutta, Z.A., and R.A. Salam. 2012. Global nutrition epidemiology and trends. Annals of Nutrition \& Metabolism 61 (1): 19.

Bonita, Ruth, Roger Magnusson, Pascal Bovet, Dong Zhao, Deborah C. Malta, Robert Geneau, Il Suh, Kavumpurathu Raman Thankappan, Martin McKee, James Hospedales, Maximilian de Courten, Simon Capewell, and Robert Beaglehole. 2013. Country actions to meet UN commitments on noncommunicable diseases: A stepwise approach. The Lancet 381 (9866): 575-584. https://doi.org/10.1016/S0140-6736(12)61993-X.

Bonnefoy, J, A. Morgan, M.P. Kelly, J. Butt, and V. Bergman. 2007. Constructing the evidence base on the social determinants of health: A guide. In Measurement and Evidence Knowledge Network (MEKN). Universidad del Desarrollo, Chile, and National Institute for Health and Clinical Excellence, Manchester.

Cramer, C., D. Johnston, C. Oya, and J. Sender. 2017. Fairtrade and labour markets in Ethiopia and Uganda. Journal of Development Studies 53 (6): 841-856.

Dangour, A.D., E. Kennedy, and A. Taylor. 2013. Commentary: The changing focus for improving nutrition. Food and Nutrition Bulletin 34 (2): 194.

Dorfman, L., and L. Wallack. 2007. Moving nutrition upstream: The case for reframing obesity. Journal of Nutrition Education and Behavior 39 (2): S45-S50.

Downie, R. 2016. Sustaining Improvements to public health in Ethiopia. A Report of CSIS Global Health Policy Center.

Embassy of the Federal Democratic Republic of Ethiopia. 2016. Disaster Prevention and Preparedness Commission.

Ethiopia Central Statistical Agency and ICF International. 2012. 2011 Ethiopia Demographic and Health Survey: Key findings. Addis Ababa, Ethiopia and Calverton, Maryland, USA: Central Statistical Agency and ICF International.

Ethiopian Academy of Science. 2013. Report on integration of nutrition into agriculture and health in Ethiopia. Addis Ababa: Ethiopian Academy of Science.

Federal Democratic Republic of Ethiopia. 1996. National food security strategy. Addis Ababa. Ababa. 
2016. Growth and Transformation Plan II (GTP II) $(2015 / 16-2019 / 20)$. Addis Ababa.

Federal Ministry of Health. 2008. National Nutrition Strategy. http://www.iycn. org/files/National-Nutrition-Strategy.pdf

FMoH/UNICEF/EU Situation Analysis of the Nutrition Sector in Ethiopia: 2000-2015. 2016. Ethiopian Federal Ministry of Health, UNICEF and European Commission Delegation.

Garrett, J., and M. Natalicchio. 2011. Working multisectorially in nutrition: Principles, practices and case studies. IFPRI.

Gillespie, Stuart, Lawrence Haddad, Venkatesh Mannar, Purnima Menon, Nicholas Nisbett, and Maternal, and Child Nutrition Study Group. 2013. The politics of reducing malnutrition: Building commitment and accelerating progress. The Lancet 382 (9891): 552-569.

Government of the Federal Democratic Republic of Ethiopia. 2013. National Nutrition Programme: June 2013-June 2015.

- 2016. National Nutrition Programme II: 2016-2020.

Hazards and Vulnerability Research Institute. 2014. The 1983-1985 Ethiopian Famine. http://webra.cas.sc.edu/hvri/feature/oct2013_dom.aspx

Heaver, R. 2005. Strengthening country commitment to human development: Lessons from nutrition directions in development series. Washington, DC: The World Bank.

Hoey, L., and D.L. Pelletier. 2011. The management of conflict in nutrition policy formulation: Choosing growth-monitoring indicators in the context of dual burden. Food and Nutrition Bulletin 32 (2 Suppl): S82-S91.

International Food Policy Research Institute. 2015. Global nutrition report. Washington, DC: IFPRI.

Kanter, R., H.L. Walls, M. Tak, F. Roberts, and J. Waage. 2015. A conceptual framework for understanding the impacts of agriculture and food system policies on nutrition and health. Food Security 7 (4): 767-777.

Kassebaum, N.J. 2014. Global, regional, and national levels and causes of maternal mortality during 1990-2013: A systematic analysis for the Global Burden of Disease Study 2013. The Lancet 384 (9947): 980-1004.

Kassie, B.T., H. Hengsdijk, R.P. Rotter, H. Kahiluoto, S. Asseng, and M. van Ittersum. 2013. Adapting to climate variability and change: Experience from cereal-based farming in the Central Rift and Kobo valleys, Ethiopia. Environment Management 52 (5): 1115-1131.

Kassie, B.T., R.P. Rotter, H. Hengsdijk, and S. Asseng. 2014. Climate variability and change in the Central Rift Valley of Ethiopia: Challenges for rainfed crop production. The Journal of Agricultual Science 152 (1): 58-74.

Keller, E.J. 1992. Drought, war and the politics of famine in Ethiopia and Eritrea. The Journal of Modern African Studies 30 (4): 609-624. 
Kennedy, E., M. Tessema, T. Hailu, D. Zerfu, A. Belay, G. Ayana, D. Kuche, T. Moges, T. Assefa, A. Samuel, T. Kassaye, H. Fekadu, and J. van Wassenhove. 2015. Multisector nutrition program governance and implementation in Ethiopia: Opportunities and challenges. Food and Nutrition Policy 36 (4): S34-S48.

Lachat, Carl, Stephen Otchere, Dominique Roberfroid, Abubakari Abdulai, Florencia Maria Aguirre Seret, Jelena Milesevic, Godfrey Xuereb, Vanessa Candeias, and Patrick Kolsteren. 2013. Diet and physical activity for the prevention of noncommunicable diseases in low-and middle-income countries: A systematic policy review. PLoS Medicine 10 (6): el001465.

Lasswell, H.D. 1990 [1936]. Politics; who gets what, when, how. Gloucester: Peter Smith Publisher.

Lowndes, V., and M. Roberts. 2013. Why institutions matter: The new institutionalism in political science. Basingstoke: Palgrave Macmillan.

Malik, V.S., W.C. Willet, and F.B. Hu. 2013. Global obesity: Trends, risk factors and policy implications. National Review of Endocrinology 9: 13-17.

March, J.G., and J.P. Olsen. 1984. The new institutionalism: Organizational factors in political life. The American Political Science Review 78 (3): 734-749.

- 2011. The logic of appropriateness. In The Oxford handbook of public policy, ed. R.E. Goodin, M. Moran, and M. Rein. Oxford: Oxford University Press.

Marmot, M. 2005. Social determinants of health inequalities. Lancet 365: 1099-1104.

Mendis, S. 2010. The policy agenda for prevention and control of noncommunicable diseases. British Medical Bulletin 96: 23-43.

Mills, M.E. 1990. Conflict resolution and public policy. New York: Greenwood Press.

Ministry of Health. 2015. Health Sector Transformation Plan (HSTP). The Federal Democratic Republic of Ethiopia, Ministry of Health.

Nabyonga-Orem, J., and R. Mijumbi. 2015. Evidence for informing health policy development in Low-income Countries (LICs): Perspectives of policy actors in Uganda. International Journal of Health Policy and Management 4 (5): 285-293.

Nisbett, N., E. Wach, L. Haddad, and S. El Arifeen. 2015. What drives and constrains effective leadership in tackling child undernutrition? Finding from Bangladesh, Ethiopia, India and Kenya. Food Policy 53: 33-45.

Nutley, S.M., I. Walter, and H.T.O. Davies. 2007. Using evidence: how research can inform public services. Bristol: The Policy Press.

Parkhurst, J.O. 2017. The politics of evidence: from evidence based policy to the good governance of evidence. Abingdon: Routledge. 
Pelletier, D.L., E.A. Frongillo, S. Gervais, L. Hoey, P. Menon, T. Ngo, R.J. Stoltzfus, A.M. Ahmed, and T. Ahmed. 2012. Nutrition agenda setting, policy formulation and implementation: Lessons from the mainstreaming nutrition initiative. Health Policy \& Planning 27 (1): 19-31.

Peters, B.G. 2008. Institutional theory: Problems and prospects. In Debating institutionalism, ed. B.G. Peters In J. Pierre and G. Stoker, 1-21. Manchester: University of Manchester Press.

Reda, A. 2015. Achieving food security in Ethiopia by promoting productivity of future world food tef: A review. Advances in Plants \& Agriculture Research $2(2), 45$.

Reinhardt, K., and J. Fanzo. 2014. Addressing chronic malnutrition through multi-sectoral, sustainable approaches: A review of the causes and consequences. Frontiers in Nutrition 1: 13.

Roberto, C.A., B. Swinburn, C. Hawkes, T.T.K. Huang, S.A. Costa, M. Ashe, L. Zwicker, J.H. Cawley, and K.D. Brownell. 2015. Patchy progress on obesity prevention: Emerging examples, entrenched barriers, and new thinking. The Lancet 385 (9985): 2400-2409.

Roberts, W. 2008. The no-nonsense guide to world food. Toronto: New International Publications, Ltd.

Ruel, M.T., H. Alderman, and Maternal and Child Nutrition Study Group. 2013. Nutrition-sensitive interventions and programmes: How can they help to accelerate progress in improving maternal and child nutrition? The Lancet 382 (9891): 536-551.

Secorun, L. 2016. Teff could be the next quinoa as Ethiopia boosts exports. https://www.theguardian.com/sustainable-business/2016/oct/14/teffquinoa-ethiopia-boosts-exports-food-africa

Shiffman, Jeremy. 2006. Donor funding priorities for communicable disease control in the developing world. Health Policy and Planning 21 (6): 411-420. https://doi.org/10.1093/heapol/czl028.

Smith, K.E. 2013. Beyond evidence based policy in public bealth. London: Palgrave Macmillan.

Tebekaw, Y., C. Teller, and U. Colon-Ramos. 2014. The burden of underweight and overweight among women in Addis Ababa, Ethiopia. BMC Public Health 14: 1126.

Trivedi, P. 2000. How to evaluate performance of government agency: A manual for practitioners. World Bank.

USAID. 2016. Ethiopia. https://www.usaid.gov/ethiopia

Walls, H.L., L. Cornelsen, K. Lock, and R.D. Smith. 2016a. How much priority is given to nutrition and health in the EU Common Agricultural Policy? Food Policy 59: 12-23.

Walls, H.L., S. Kadiyala, and R.D. Smith. 2016b. Research and policy for addressing malnutrition in all its forms. Obesity 24 (10): 2032. 
Webb, P., and J. von Braun. 1994. Famine and food security in Ethiopia: Lessons for Africa. Chichester: Wiley.

Weiss, C.H. 1979. The many meanings of research utilization. Public Administration Review 39 (5): 426-431.

WHO. 2013. Global nutrition policy review: What does it take to scale up nutrition action? Geneva: World Health Organization.

World Bank. 2013. Improving mutrition through multisectoral approaches. Washington, DC: World Bank.

World Food Programme. 2017. Productive Safety Net Programme in Ethiopia. https://www.wfp.org/content/protective-safety-net-programme-ethiopia

Zello, G.A. 2015. Natinal nutrtion programs in emering countries: Coping with the double burden of malnutrition and obesity in Ethiopia. Canadian Journal of Diabetes 39: S4.

Open Access This chapter is licensed under the terms of the Creative Commons Attribution 4.0 International License (http://creativecommons.org/licenses/ by $/ 4.0 /)$, which permits use, sharing, adaptation, distribution and reproduction in any medium or format, as long as you give appropriate credit to the original author(s) and the source, provide a link to the Creative Commons license and indicate if changes were made.

The images or other third party material in this chapter are included in the chapter's Creative Commons license, unless indicated otherwise in a credit line to the material. If material is not included in the chapter's Creative Commons license and your intended use is not permitted by statutory regulation or exceeds the permitted use, you will need to obtain permission directly from the copyright holder.

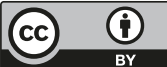

